\title{
Adaawk: Thinking and being in our hearts-Sharing the reflections of Otsin, Gitxsan rural indigenous nursing practice
}

\author{
Sheila Blackstock ${ }^{* 1,2}$ \\ ${ }^{1}$ University of Alberta, Edmonton Alberta, Canada \\ ${ }^{2}$ Thompson Rivers University, BC, Canada
}

Received: May 30, 2019

DOI: $10.5430 /$ jnep.v9n9p123
Accepted: June 21, 2019

Online Published: June 25, 2019

\begin{abstract}
Adaawk is oral history shared through the reflections of the first offering of a Gitxsan rural nursing practice course in follow up to the publication Otsin: Sharing the spirit of an indigenous nursing practice course development. In the spirit of adaawk, the Gitxsan's reflections of the Gitxsan nursing practice course are themed using the metaphor of a totem pole. Each concept, and partnerships are integral to the development of a totem that reflects the adaawk. The purpose of this article is to demonstrate how the co-creation of relational concepts with the community strengthens preceptor, student and community partnerships for improved preceptor support and student learning outcomes. The author's reflections demonstrate how the rural Gitxsan nursing practice experience informs the co-creation of cultural safety knowledge. Further, the experience provides a safe forum for students to practice cultural safety and relational practice. It allows students to co-create innovative patient outcomes within rural and community nursing practice context reflecting a two-eyed seeing approach. Students give back to communities through facilitated student placements in leadership/community health nursing for a fourth year nursing practice project with Gitxsan and rural communities in follow up to their third year practice. Authentic community partnerships and co-creation are foundational to enacting relational practice to nursing practice course development, consultation, and cultural safety practice. Learning outcomes of the course are revised to strengthen the parts of the totem and ultimately the essence of adaawk.
\end{abstract}

Key Words: Indigenous, Rural nursing practice, Curriculum, Pedagogy, Student-centered, Nursing students

\section{INTRODUCTION}

Interdisciplinary tenets of western nursing ontologies and epistemologies are woven with Indigenous ways of knowing and being to reflect community partnerships, rural practice and an opportunity to practice cultural safety. ${ }^{[1]}$ The metaphor of cedar strips reflects the role of each piece strengthening one another as they are woven together to reflect the students' co-construction of Gitxsan Indigenous knowledge as they learn traditional ways of knowing and being during a rural Indigenous nursing practice course ${ }^{[1]}$ at the end of a third year undergraduate degree.

In the bush, an Elder guides the students across mossy ground under a canopy of majestic cedar trees. The Elder shares the importance of finding a tree that is straight, healthy, and once a tree is selected to honour the tree with a song, a tobacco offering to acknowledge the spirit of the tree, its gifts, the creator, animal and the heart/soul of spiritual beings. Cedar

*Correspondence: Sheila Blackstock; Email: sblackst@ualberta.ca; Address: University of Alberta, Edmonton Alberta, Canada. 
is harvested by taking only a strip from a tree during it's lifespan to ensure sustainability and longevity of the tree. Elders say that we must as Gitxsan academics remember to move from always thinking with our minds to getting back to thinking and speaking from our heart-where we began. In the same manner of being rooted in the heart it is important to reflect being rooted in Gitxsan oral history "adaawk" and to create new pedagogical nursing knowledge that reflects Indigenous academics journeys with their communities. In time immemorial, the totem details adaawk and metaphorically represents the Gitxsan rural nursing practice course in partnership with community. Each concept and partnership are integral to the development of a totem that reflects the adaawk.

The purpose of this article is to reflect on the development and delivery of the Gitxsan rural nursing course ${ }^{[1]}$ providing an innovative pedagogical approach to working in partnership to improve Indigenous health outcomes. The author shows how the co-creation of relational concepts with the community strengthens preceptor, student and community partnerships for improved preceptor support and student learning outcomes. Gitxsan traditional villages (Gitwangak, Gitsegukla, Gitanmax, Glen Vowell and Kispiox) are situated in two provincial municipalities (Hazelton and New Hazelton) in north western area of British Columbia. Gitxsan people use the Wilp and Clan systems to govern their society. The Gitxsan Peoples are organized through kinship lines. A person is born into a particular Wilp and Clan. The Gitxsan have a matrilineal system with House members tracing their lineage through their mother's side. All Gitxsan belong to a Wilp (i.e., house group) which is the basic unit for social, economic and political purposes. Wilps consists of a collection of closely related people.

The Gitxsan Peoples are rich in their traditional culture and knowledge. The metaphor of carving a totem is used to represent the pedagogical tenets. A student-centered teaching philosophy and Indigenous ways of knowing are used to synthesize the first rural Gixsan nursing practice course offering. Secondly, the author's journal reflections and synthesis inform course revisions, further community partnerships, and leadership projects for the students progressing in their fourth year of practice.

\section{Problem statement}

There is a scarcity of Indigenous, rural nursing practice undergraduate education courses. The Truth and Reconciliation Commission Calls to Action ${ }^{[2]}$ report findings direct the academy to provide Indigenous nursing practice and requisite theory courses. Further, the First Nations Health Authority (FNHA) indicates that rural Indigenous nursing courses are needed in undergraduate education to provide the training and education to prepare new graduates to work within Indigenous communities. ${ }^{[3]}$ Despite innovations to offer rural nursing practice courses online, there are challenges related to delivering and preparing nurses to work in rural health ${ }^{[3,4]}$ that cannot be captured without nursing students being immersed in practice in rural, Indigenous communities. Rural nursing practice is shaped in part by the geographical context, smaller institutions, and remote access and the needs of the community. ${ }^{[4,5]}$ There are unique nuances of rural nursing practice that require ongoing training and ingenuity. These rural nuances and sense of rural community are foundational to retaining and recruitment of registered nurses which are amplified within Indigenous rural nursing practice. Explanations of rural/remote health have concluded that geography should be considered as a key determinant of both health and use of health care. ${ }^{[6-9]}$ Recently, rural/remote communities are described as 'incubators of innovation' ${ }^{\text {[9] }}$ ultimately leading to positive health outcomes for communities. Changes to break down barriers and or improve services in rural communities $^{[10]}$ are sought to sustain existing registered nurses.

\section{BACKGROUND}

The Gitxsan, rural indigenous nursing practice course was developed and delivered using a decolonizing approach in response to an invitation from the community to provide students with the opportunity to practice cultural safety and to understand the meaning of health to Gitxsan Peoples. ${ }^{[1]}$ Allowing students to live within and be a part of the community during their time in nursing practice is key and has secondary benefits of having the community members be a part of the students' cultural experiences. The extension of geography and the nuances of being in a rural community reflects the community partnerships on the one hand and on the other hand is advantageous to having students participate in potlach, salmon feasts, cultural crafts and ceremonies.

\section{Ingenuity and innovation in rural nursing practice}

Although there have been many economic losses to the rural areas due to sawmill closures, families remain for a quieter lifestyle and affordable living in the Gitxsan territories and surrounding towns. Living in rural communities inherently has both positive and negative aspects of rural life challenging the traditional understanding of the elements of a rural community. Communities that were traditionally homogeneous have evolved to include a transient nature of the population during higher tourist seasons, guiding and fishing expeditions. Some academics have professed that the idyllic 'community' sense of reciprocity, neighbourliness and caring is relied upon in place of community and in home care services in rural communities. ${ }^{[11]}$ Rural culture has evolved 
from the conventional definition to a relational definition of rural community with a strong positive small-town milieu where local agency is a central feature to coping with lack of resources and the importance of reciprocity are valuable community assets. Local agency refers to being innovative to compensate for a lack of human and material resources. Reciprocity is the sense of neighbourliness and caring that evolves from being within/seen in the community, interacting with Knowledge Keepers, Elders, youth and peers. The students nurses are newcomers to the community. As a newcomer to the community and a health professional being in community is integral to developing relationships and community partnerships to co-create positive health outcomes.

Intentional engagement as a nurse working with Indigenous Peoples begins through immersing our authentic selves in community. Participation in gatherings, fishing, berry picking, cedar gathering is as a starting point of 'being in community' demonstrating transparency and builds relationships with community members. Intentionality leads to opportunities to layer health promotion/prevention activities, teaching and a reciprocal familial context where community members teach nurses about the local culture, language and Indigenous ways of being ${ }^{[12]}$ as it relates to health. Recent findings of an integrative review of relational nursing coined this intentionality of nursing presence as being 'intentionality with a purpose' ${ }^{[12]}$ An Indigenous rural nursing practice course in undergraduate education provides students with an opportunity to be guided by the community in culturally safe practices on the one hand and on the other hand learn the ingenuity of rural nursing practices.

Canadian Indigenous Peoples are disproportionately represented in poorer health outcomes and double the agestandardized mortality rates compared to Canadian population. ${ }^{[13,14]}$ Indigenous Peoples are over represented with chronic conditions such as hypertension, diabetes and heart conditions correlated to disparities linked to access, cultural safety ${ }^{[15]}$ and the social determinants of health. ${ }^{[16]}$ Epidemiological evidence indicates these factors are multiplied in rural and remote contexts ${ }^{[17-19]}$ and in some cases chronic diseases are undiagnosed. ${ }^{[16]}$ Researchers have illuminated the important distinction of community members' experiences within rural and remote geographical locations as being a much higher level of anxiety in relation to health issues that arise in remote contexts, the training of health personnel in dealing with presenting health issues and health organizations and services being relevant and responsive to the local community needs. ${ }^{[15]}$ These findings highlight the importance of training nurses to provide appropriate, cultural care and developing locally appropriate and relevant health services/programs to be responsive to the community. ${ }^{[20-22,27]}$

Published by Sciedu Press
There is a scarcity of Indigenous rural nursing practice courses in British Columbia, thus there are minimal resources and publications to guide the reflective process. ${ }^{[23]}$ The author based their journal reflections on Indigenous ways of knowing and being informed by relational practice. It is important to use reflexivity as a faculty member and as a Gitxsan person to inform changes to the course.

\section{ADAAWK}

\subsection{Adaawk: Totem Pole}

The metaphor of carving a totem is used to represent Gitxsan ways of knowing and being, cultural safety through respect, responsibility, relevance and reciprocity; ${ }^{[24]}$ context based pedagogical tenets; a student centered philosophy; ${ }^{[25]}$ two eyed seeing approach; ${ }^{[28,29]}$ and, the themes identified in the author's reflections (see Figure 1), and knowledge translation. Subsequent work involves using a relational framework to evaluate the community and student evaluations' and will be documented in future articles. A student-centered teaching philosophy and Indigenous ways of knowing are used as a foundation to reflect on the author's perceptions of the outcomes of the first rural Gitxsan nursing practice course offering from $2018 .{ }^{[1]}$

\subsection{Gathering Cedar: Gitxsan ways of knowing and be- ing}

Gitxsan Peoples welcomed the students from the moment they arrived. Students experienced a warm welcome be community members as they settled into the nurses residences. The students got their bearings through acquainting themselves with the town site after a long drive north from their homes. Local agencies, bands gatherings, radio and in the newspapers announced the nursing student's impending arrival to the community. The community understood that the nursing students were coming to practice in rural practice and to be in community to learn with registered nurses working on reserve for a total of 6 weeks. The community members, Elders, and Knowledge Keepers shared the Gitxsan ways of knowing and being, at every student encounter. The students walked alongside the community members in practice and on the land experiences. Students picked poplar seed buds and made salve, gathered cedar strips, cleaned and cut them all the while learning the Gitxsan language, singing songs, feasting and learning from the wisdom of Elders, youth, parents and peers. The students are taught about the medicines from the creator in the bush by Knowledge Keepers and Elders. In Gitxsan culture individuals are chosen to learn about medicines that in turn practice traditional medicine-anyone else who teaches others but has not had a bundle passed onto them are practicing bad medicines. Students learn the importance of understanding protocol, who respected El- 
ders/Knowledge Keepers are and how to engage in protocol. The students are given gifts at the start of the course and were responsible to give gifts through-out their practicum to Knowledge Keepers, Elders and community members. They learn how to prepare some of the medicines and use them by community members practicing traditional ways of healing. The health agency in community bought the supplies and a facilitator for each student to make their own drum to take home with them. They are taught what it means to have a drum and their responsibilities in owning one and taking care of it to insure it's used in a good way.

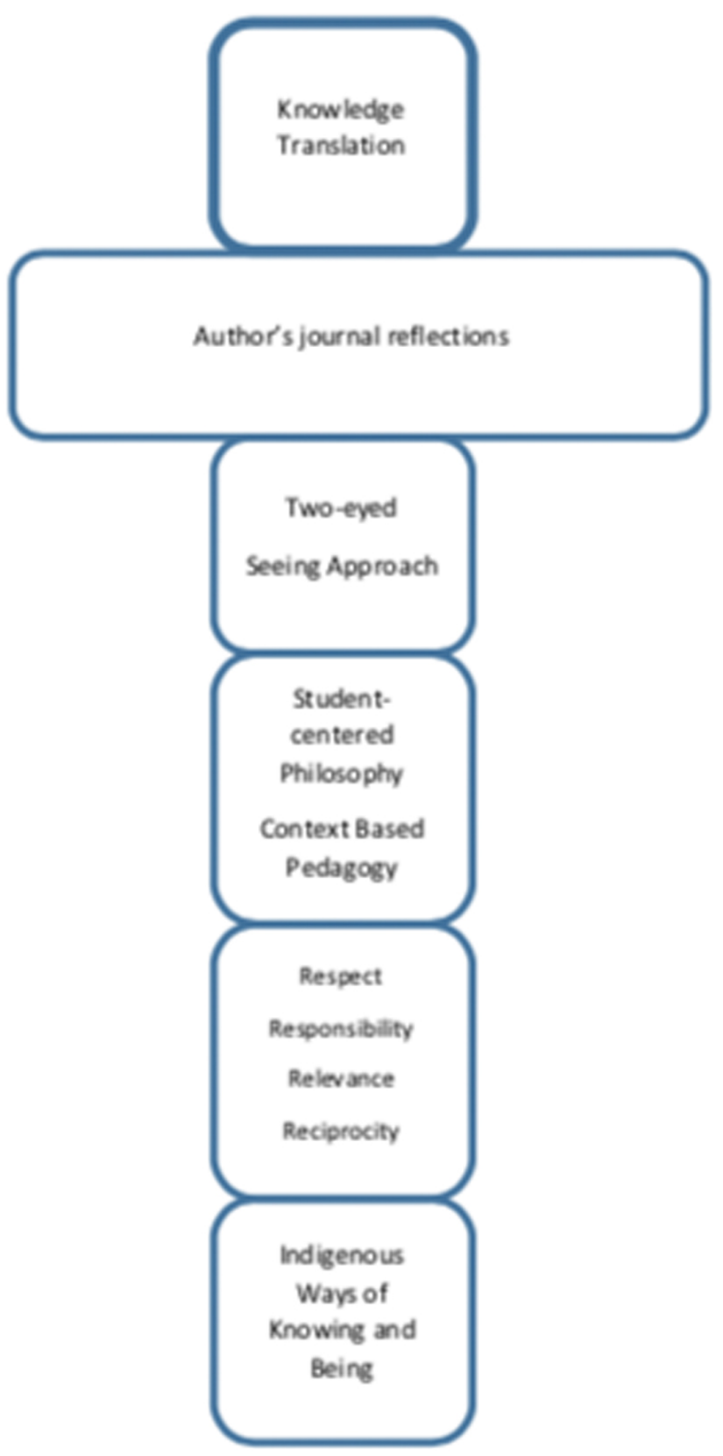

Figure 1. Totem Concepts. Gathering Cedar: Gitxsan Indigenous Ways of Knowing and being. Weaving Cedar Strips: Ingenuity in rural nursing practice; Respect, Responsibility, Relevance \& Reciprocity; context based pedagogy; student-centered philosophy; two-eyed seeing approach. Authors reflective journaling using relational practice concepts; Knowledge translation.

\subsection{Weaving cedar strips}

Respect, responsibility, relevance and reciprocity are key practices to ensuring cultural safe nursing practices; a way of decolonizing health care provision. ${ }^{[20]}$ Being in rural Indigenous community provides a foundation for students' confidence and abilities to practice cultural safety. They coconstructed their way of being cultural safe with the guidance of Gitxsan community members, Knowledge Keepers and their nursing preceptor. While gathering on the land they come to understand the importance of reciprocity as it relates to giving an offering to the trees for allowing the gathering of cedar strips, and giving back to community through fourth year community projects.

\subsection{Pedagogy, philosophy and two-eyed seeing approach}

A student-centered learning ${ }^{[25]}$ approach shifts the focus of learning from the teacher to the student; a shift that enhances student's capacity for context-based learning ${ }^{[26]}$ to develop professional nursing practice and lifelong learning skills. Using both a context based and student-centered learning allows for evaluation, feedback that allows for responsive changes to be made during the practicum. Students becoming safely grounded through the two-eyed seeing approach ${ }^{\text {[28,29] }}$ through understanding their roles as a student nurse with one eye while learning Indigenous ways of knowing and being and practicing cultural safety while being immersed in cultural events and activities.

\subsection{Relational practice concepts}

Hermeneutic phenomenology (HP) is used in relational practice to focus on the lived experiences and how experiences are constructed on an intrapersonal, interpersonal and contextual level. ${ }^{[30]}$ The author has taught relational practice for 5 years exploring the interplay of theoretical constructs and Indigenous ways of knowing and being. The HP lens at the intrapersonal (i.e., what's going on within a person), interpersonal (i.e. what's happening between or among people) and contextual (i.e., what's going on around the people and situation). ${ }^{[30]}$ Further, a critical lens is used to understand the interplay of power laden contexts. ${ }^{[30]}$ The HP and critical lens ${ }^{[30]}$ are used as a lens to review the author's reflective journals and experiences resonating with a two eyed seeing approach. Researchers have used tenets of relational practice focusing on Doane and Varcoes' ${ }^{\text {[30] }}$ attending to spirit to review the epistemological and ontological underpinnings of undergraduate curriculum ${ }^{[31]}$ and are used as a framework to critically reflect on the themes of the author's journal reflections, the conceptual tenets relating to student (see Table 1), and health care organizations and community(see Table 2). 
Table 1. Students

\begin{tabular}{|c|c|}
\hline Domains & Attending to Spirit (Otsin) \\
\hline \multirow{5}{*}{$\begin{array}{l}\text { Intrapersonal-reflexivity, critical } \\
\text { self-awareness. }\end{array}$} & Weekly circle talks facilitated by faculty \\
\hline & Journal reflections \\
\hline & Practicing cultural safety while being mentored by Elders, Knowledge keepers. \\
\hline & Cedar pulling, traditional medicine/nature walks \\
\hline & Coming to know myself better through traditional healing and Gitxsan cultural practices. \\
\hline \multirow{6}{*}{$\begin{array}{l}\text { Interpersonal-being in community } \\
\text { contextual knowing. }\end{array}$} & Being immersed in community \\
\hline & Engagement through cultural activities; ceremonies; \\
\hline & Professional development with other RNs and para professionals \\
\hline & $\begin{array}{l}\text { Creating cultural understanding through experiences and sharing with community leaders and } \\
\text { community members. }\end{array}$ \\
\hline & $\begin{array}{l}\text { High school and elementary school workshops and presentations on health promotion } \\
\text { initiatives and nursing. }\end{array}$ \\
\hline & Cedar weaving, making button blankets, drum making, cottonwood picking/salve making. \\
\hline $\begin{array}{l}\text { Contextual-experience shaped by } \\
\text { place, ingenuity in rural practice, } \\
\text { decolonized framework, } \\
\text { interpretations. }\end{array}$ & $\begin{array}{l}\text { Rural nursing practice- being creative with what you have.... Whether that's a lack of } \\
\text { equipment and or people. } \\
\text { Living and working on the impacts of cultural genocide as a nurse-rural and community. } \\
\text { Traditional healing and medicines deeply rooted in the land. } \\
\text { Salmon feast/honoring salmon migration. }\end{array}$ \\
\hline
\end{tabular}

Table 2. Health Care Organizations/Community

\begin{tabular}{l}
\hline Domains \\
\hline \\
Intrapersonal-reflexivity, \\
Critical self-awareness.
\end{tabular}

Interpersonal-being in community; contextual knowing.

Contextual-experience shaped by place, ingenuity in rural practice, decolonized framework, and interpretations.

\section{Attending to Spirit (Otsin)}

Creating schedules for students

Expanding our learning/leadership.

Becoming more aware of the importance of Gitxsan culture.

Understanding the importance of my professional development.

My role in quality practice.

Reflections on my experiences as a student and how that informs my role now.

Community capacity for housing.

In community with students, listening to Elders stories that have not been shared before as a result of having a student(s).

Professional development with other RNs and para professionals.

Becoming aware of quality practice issues and opportunities for change.

Creating cultural understanding through experiences and sharing with community leaders and community members.

Cultural safety through the nursing lens.

High school and elementary school workshops and presentations on health promotion initiatives and nursing.

Rural nursing practice-many students from different institutions

Opportunities for student leadership projects to develop preceptor manuals, student orientation manuals.

Assisting students to make the connection between colonization and holistic health outcomes of Indigenous Peoples.

Two-eyed seeing: western and traditional ways of knowing and being.

Sharing the culture rich in Gitxsan ways of knowing and being. 


\subsubsection{Students}

Intrapersonal level. The weekly sharing circles facilitated by the author provided a forum for students to share their experiences, co-construction of their understandings of Indigenous ways of knowing/being and cultural safety practices. They shared how they began to understand how protocol honors and empowers by breaking down western colonial practices both in community and within the health care organizations. As the students learn how to introduce themselves in Gitxsan, common sayings and names associated with the land both in community and in the hospital settings it creates a foundation for a relationship with individuals and community members. Further, students participate in healing circles in community dealing with the affects of residential school, trauma, abuse and neglect which began to unfold personal experiences that often allows them to come to know themselves better [italics reflect themes from the author's journal].

Interpersonal level. Having the lived experiences of being in community through work and practice allows students to be a part of the community through nursing practice as well as participating in cultural events. At times students had the clinical experience of a patient dying and are asked to participate in a potlatch ceremony that celebrates the life of the individual. I could see that this experience was received as being humbled and honoured to be a part of the community and enriched their understanding of Gitxsan Peoples and their traditions and cultures. The potlatch ceremony starts in the late afternoon and goes into the early morning allowing for each of the clans to offer their support to the family clan. During this time students hear stories from the chiefs, Wilps, Knowledge Keepers, and Elders explaining the meaning behind the ceremonies. At other times when the students were gathering cedar, poplar buds, making button blankets and weaving cedar they heard stories from the community members of their experiences on the land. Often mothers bring their children during the gathering on the land and students witnessed the passing of traditions and knowledge from Elders, community members and parents to the children. In this manner the students began to understand what it means to have the community involved in raising the children.

Contextual level. Rural Indigenous nursing practice means being creative with what you have-whether it's a lack of supplies or human resources. Students shared examples of how their preceptors, interprofessional (i.e., paraprofessionals and professionals) were able to collectively come up with innovative solutions to meet the needs of the clients. Students marvelled about the expertise and precision in which the teams worked in collaboration in spite of not having specialized teams to respond to codes or difficult intravenous insertions. In the community setting, students gained in- sights on how other team members take the lead to insure patient and nursing priorities are met through an Indigenous lens. They were taught how traditional medicines were used and at times without western medicines by the interprofessional team. The contextual level in rural Indigenous practice means being on the land; in ceremony, dancing, drumming, singing, feasts, gathering, sewing, weaving and being with peers.

\subsubsection{Health care organizations \& community}

Intrapersonal level. In community the preceptors were both community members and preceptors to the students. In this manner, empowerment through sharing their knowledge of Gitxsan culture, traditions, language and western knowledge of nursing practice results. Preceptoring students assists in acknowledging the importance of their professional development through sharing professional development opportunities with the students such as workshops on Elder abuse, residential school survivor circles, and addictions.

Interpersonal level. When preceptors are in community with the students, they hear stories being shared by Elders to the students that they have not been shared before [or had the opportunity to hear] creating space and place for sharing as a result of having students. Students bring updated knowledge around best practices and provided an opportunity for change resulting in fourth year projects for the students. Community members are a part of the audience in some of the nursing student presentations on health promotion to elementary and high school students.

Contextual level. Having students within a rural and Indigenous communities to practice is different for the health care organizations and the community members. The hospitals have students from different universities which presents an opportunity to create a preceptor and student manual that is specific to our students. A two-eyed seeing approach allows health care organizations to learn from and through the student's experiences and presented opportunities for future conversations of collaborating with Indigenous nurses and community members. Having the students practice both within the hospital setting and Indigenous health setting allows students to see the impacts of colonization as it relates to the history of Indian Hospitals and mistrust of community members, to access services, although hospitals are beginning to decolonize the practice setting.

\subsection{Knowledge translation}

Knowledge translation from the student's perspective will mean sharing their experiences with upcoming nursing students to insure they were aware of the rural Indigenous nursing practice course and importantly the amazing impact the 
Gitxsan Peoples had on their lives. The students will also give back through fourth year community health nursing projects such as: a preceptor manual and student manual for the hospital; first contact health information; and a literature review for a diagnostic/trauma center.

\section{Conclusion: Getting BaCk to being IN OUR HEARTS}

The Indigenous rural nursing practice experience culminates where it began- in the bush, on the land near the canopies of tall cedar trees where students make their first drum over a two day workshop. The drum, Knowledge Keepers say, represents your heart being born or reborn it is important to have your body and mind in the right place and to be thinking healthy, good thoughts as this energy is transmitted into their drum. It's difficult to translate to the reader the impact of the student's practice experience, participating in cultural events, making salve, gathering cedar, making button blankets and drums. Their oral reflections will reflect the richness of the nursing practice experience and importantly the understanding of rural practice along with the honor or living and learning with Gitxsan Peoples.

This narrative is an opportunity to share the author's lived experiences of developing and teaching a rural Indigenous nursing practice course. The health care organizations and community are eagerly awaiting next year's cohort and have once again taken a leadership role in arranging community events and cultural experiences. In terms of my role as a Gitxsan nursing faculty member, I am humbled and honored to be a part of the process and continue my journey of thinking and being back in my heart.

\section{ACKNOWLEDGements}

Respectfully acknowledge the Elders, Knowledge Keepers, Gitxsan Peoples, preceptors, health care organizations and community members.

\section{CONFLicts OF InTEREST Disclosure}

The author declares there is no conflict of interests.

\section{REFERENCES}

[1] Blackstock S. Otsin: Sharing the Spirit-Development of an Indigenous Rural Nursing Practice Course. Journal of Nursing Education and Practice. 2018; 8(12): 29-35. https://doi .org/10.5430/jn ep.v8n12p29

[2] Truth and Reconciliation Commission of Canada [TRC]. 2015. Calls to action. Winnipeg, MB: TRC. Available from: http//www.trc.ca/websites/trcinsitituions/File/201 5/Findings/Exec_Summary_2015_05_31_web_e.pdf

[3] First Nations Health Authority: Health through wellness: Nursing Review. 2015. Available from: http///www.fnha.ca/what-we-d -o/nursing-services

[4] MacLeod MLP, Lindsey AE, Ulrich $\mathrm{CH}$, et al. The development of a practice-driven, reality based program for rural acute care registered nurses. Journal of Continuing Education in Nursing. 2008; 39(7): 298-304. https://doi .org/10 .3928/00220124-20080 701-03

[5] Skinner MW, Rosenberg MW, Lovell SA, et al. Services for seniors in small town Canada: the paradox of community. Canadian Journal of Nursing Research. 2008; 40(1): 80-101.

[6] DesMeules M, Pong R. How health are rural Canadians? An assessment of their health status and health determinants. Ottawa: Canadian Institute for Health Information, September. 2006.

[7] Lavergne M, Kerphart G. Examining variations in health within rural Canada. Rural and Remote Health. 2012; 12: 1848.

[8] Luginaah I. Health geography in Canada: Where are we headed? The Canadian Geographer. 2009; 53(1): 91-99. https ://doi .org/10 $.1111 / j .1541-0064.2009 .00239 . x$

[9] Wilson K, Rosenberg M. The geographies of crisis: Exploring accessibility to health care in Canada. The Canadian Geographer. 2002; 46(3): 223-234. https://doi.org/10.1111/j.1541-0064.20 $02 . \mathrm{tb} 00742 \cdot \mathrm{x}$

Published by Sciedu Press
[10] Bourke L, Humphreys J, Wakerman J, et al. From 'problemdescribing' to 'problem-solving': Challenging the 'deficit' view of remote and rural health. Australian Journal of Rural Health. 2010; 18: 205-209. PMid:21040082 https://doi .org/10.1111/j.14 40-1584.2010.01155.x

[11] Baumann A, Hunsberger M, Blythe J, et al. The new healthcare worker: The implications of changing employment patterns in rural and community hospitals. Health Human Resource Series (6). Ontario: McMaster University. 2006.

[12] Harry L. Exploring relational nursing with Canada's Aboriginal Peoples: An integrative literature review. (Unpublished mater's thesis). University of Victoria, Victoria, British Columbia, Canada. 2014.

[13] Caron NR. Getting to the root of trauma in Canada's Aboriginal population. Canadian Medical Association Journal. 2005; 172: 1023-1024. PMid:15824407 https ://doi.org/10.1503/cmaj. 050304

[14] Lix LM, Bruce S, Sarkar J, et al. Risk factors and chronic conditions among Aboriginal and non-Aboriginal populations. Health Report. 2009; 20: 21-19.

[15] Curran J, Ritchie SD, Beardy J, et al. Conceptualizing and managing medical emergencies where no formal paramedical system exists: Perspectives from a remote Indigenous community in Canada. International Journal of Environmental Research and Public Health. 2018; 15(2): 267-281. PMid:29401706 https ://doi .org/10.3390/ij erph15020267

[16] King M. Chronic diseases and mortality in Canadian Aboriginal Peoples: Learning from the knowledge. Preventing Chronic Disease. 2010; 8(1): A07.

[17] MacMillan HL, Walsh CA, Jamieson E, et al. The health of Ontario First Nations People: Results from the Ontario Frist Nations regional health survey. Canadian Journal of Public Health. 2003; 94: 168-171.

[18] DesMeules M, Pong R, Lagace C, et al. How health are rural Canadians? An assessment of their health status and health determi- 
nants; Canadian institute for health information Canada: Ottawa, ON, Canada. 2006

[19] Mew EJ, Ritchie SD, VanderBurgh D, et al. An environmental scan of the emergency response systems and services in remote First Nations communities in northern Ontario. International Journal Circumpolar Health. 2017; 76: 1-10. PMid:28494638 https: //doi.org/10.1080/22423982.2017.1320208

[20] Curran J. Building resilience and community capacity: The sachigo lake wilderness emergency response education initiative. Master's thesis, Laurentian University, Sudbury, ON, Canada. 2014.

[21] Blackstock SY. Shifting the academic lens: Development of an Interdisciplinary Indigenous Health Course. Journal of Nursing Education and Practice. 2017; 7(1): 11-16. https://doi.org/10.5430/jn ep.v7n1p11

[22] Blackstock SY. Indigenous Research Place and Protocol. Knowledge Makers. 2017; 2: 99-21.

[23] Kulig JC, Kilpatrick K, Moffitt P, et al. Rural and remote nursing Practice: An updated document analysis. Lethbridge: University of Lethbridge. 2013.

[24] Blanchet-Cohen N, Richardon/Kinewesquao C. Foreward: fostering cultural safety across contexts. AlterNative. 2017. https ://doi . or g/10.1177/1177180117714139
[25] Young LE, Paterson BL. Teaching Nursing: developing a student learning environment, Kors, E. (Ed). Lippincott Williams \& Wilkins: Philadelphia, PA. 2007.

[26] Savery J, Duffy T. Problem based learning: An instructional model and its constructivist frame-work. Educational Psychology, Sept-Oct. 1995; 31-38.

[27] United Nations. United Nations Declaration on the Rights of Indigenous Peoples. 2010.

[28] Marshall M, Marshall A, Bartlett C. Two-eye seeing in medicine: In Greenwood, M., De Leeuw, S., Lindsay, N.M., Reading, C. (Eds). Determinants of Indigenous People's Health in Canada: Beyond the Social. Toronto, ON: Canada Scholar's Press; 2015.

[29] Bartlett C, Marshall M, Marshall A, et al. Integrative science and two-eyed seeing: Enriching the discussion framework for healthy communities. In Hallstrom, L.K., \& Guehlstorf, N.P., \& Parkes, M.W. (Eds). Ecosystems, Society and Health: Pathways through diversity, convergence, and integration. McGill-Queens University, Montreal: AU. 2015

[30] Doane G, Varcoe C. Using theoretical lenses to support relational inquiry. In How to nurse: Relational inquiry with individuals and families. Philadelphia, PA: Lippincott Williams \& Wilkens, A Wolters Kluwer business. 2015.

[31] Spadoni M, Sevean P. Relational inquiry: attending to the spirit of nursing students. Religions. 2016. https://doi.org/10.3390/ rel7030034 